\section{Commentary: Continue to imitate the nature: We are getting closer}

\author{
Can Yerebakan, MD
}

A sustained long-term treatment strategy for the treatment of aortic valve disease in the pediatric population is inevitable. Thus, this strategy should involve the entire current armamentarium of available treatment options that need to be applied individually in each and every case. The requirements for the ideal valve substitute are well known, whereas such a valve is still not available. ${ }^{1}$ A myriad of factors influence the decision-making in this population that starts with the anatomy of the valve, concomitant cardiac lesions, previous interventions, patient needs and choice, and particularly the expertise of the surgical team. ${ }^{2}$ In the younger age population, our efforts have been strongly focused on primary aortic valve repair/reconstruction before a valve replacement with a bioprosthetic or mechanical valve substitute. Meanwhile, excellent results after the Ross procedure in specialized centers including the most recent technical modifications continue to challenge every novel surgical technique that is to be introduced to our surgical practice for aortic valve reconstruction or replacement. ${ }^{3,4}$ Longer-term outcome data will determine in which order our treatment options will be applied because aortic valve disease in younger patients remains a lifelong challenge.

In this issue of the Journal, Wiggins and colleagues ${ }^{5}$ provide an extensive outcome analysis of complex aortic valve reconstruction with tricuspidalization by neotricuspidalization (Ozaki procedure, $\mathrm{n}=40$ ) or single leaflet reconstruction $(\mathrm{n}=18)$ in 58 children and young adolescents. ${ }^{5}$ In 22 patients, balloon valvuloplasty was performed before the surgical procedure. The authors made individual decisions for the surgical procedure of choice on each patient using preoperative and perioperative

\footnotetext{
From the Department of Cardiovascular Surgery, Children's National Heart Institute, Children's National Health System, The George Washington University School of Medicine and Health Sciences, Washington, DC.

Disclosures: Author has nothing to disclose with regard to commercial support.

Received for publication Dec 31, 2019; revisions received Dec 31, 2019; accepted for publication Dec 31, 2019; available ahead of print Feb 12, 2020.

Address for reprints: Can Yerebakan, MD, Department of Cardiovascular Surgery, Children's National Heart Institute, Children's National Hospital, The George Washington University School of Medicine and Health Sciences, 111 Michigan Ave NW, Washington, DC 20010 (E-mail: cyerebakan@childrensnational.org). J Thorac Cardiovasc Surg 2020;159:2381-2 $0022-5223 / \$ 36.00$

Copyright (c) 2020 by The American Association for Thoracic Surgery https://doi.org/10.1016/j.jtcvs.2019.12.105
}

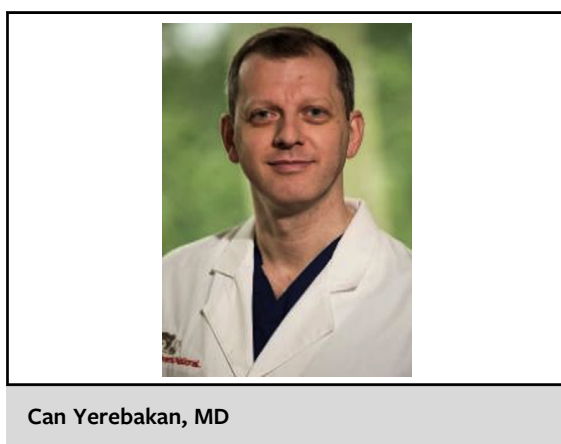

\section{CENTRAL MESSAGE \\ Tricuspidalization for aortic valve reconstruction in young patients works. Keep a close eye on the long-term outcome.}

3-dimensional echocardiographic imaging and finally their intraoperative assessment. Although the median age of the population was 14.8 years, the smallest patient who received a neo-tricuspidalization had an annular diameter of $11 \mathrm{~mm}$ (the patient underwent operation after the submission of the article) in their experience. Glutaraldehydetreated autologous pericardium or tissue-engineered bovine pericardium was used for leaflet replacement. The authors report a complete follow-up for their cohort except 1 patient. Isolated aortic regurgitation was present in $40 \%$ of the patients, and the gradient in the remaining patients was significantly reduced at a median follow-up of 14.1 months. At the last follow-up, all but 2 patients had mild or less aortic regurgitation in comparison with moderate and greater preoperatively. At a short-term follow-up, freedom from reoperation or moderate or greater aortic regurgitation was $79.0 \% \pm 8 \%$ at 3 years with no difference between both techniques. Three patients had to be reoperated because of endocarditis among the total number of 6 reoperations. Of note, there was a significant increase in aortic valve velocity in patients who received a bovine pericardial leaflet reconstruction in the follow-up. The authors have to be commended on their excellent outcome and precise description of the data and outcomes.

Because of the multifactorial decision-making, the standardization of aortic valve repair techniques remains challenging. Therefore, comparison of available data in the literature is hampered. The neo-tricuspidalization technique for the aortic valve has been shown to be effective mostly in the adult population with reproducible results. ${ }^{6}$ The translation of this promising standardized technique to younger patients was accomplished recently, and we will now be 
receiving short-term outcome results. The current study shows us that the technique can be safely and effectively applied in the pediatric and young adult population. The outcome seems minimally affected by the initial learning curve of the well-experienced surgical team; however, the number of the reoperations and endocarditis cases has to be carefully questioned. The lower limit of aortic annular size for the application of the neo-tricuspidalization is still unclear. Likewise, despite low numbers the short-term performance of the alternative bovine patch material in the aortic position raises concerns with significantly increasing aortic valve velocity and signs of degeneration. ${ }^{7}$ The bovine pericardial patch has been shown to be a safe and effective material in recent publications with a large number of implantations for various indications. ${ }^{8}$ Whether this promise will hold for aortic valve leaflet replacement in the younger age population needs to be carefully observed.

As anticipated, the fate of aortic valve reconstruction with single leaflet reconstruction or neo-tricuspidalization in this patient population will be determined by 2 primary factors that need continuous monitoring of the growth of the patient, the durability of the replacement material, and a stable effective coaptation height of the reconstructed valve. Although the current study aims to partially address these issues, these initial results seem favorable for both techniques and the autologous pericardium.

Considering further available alternatives such as mechanical and bioprosthetic valve replacement with extensively studied advantages and disadvantages, the long-term outcome of aortic valve reconstruction/repair remains the primary attractive option in the majority of the pediatric population. ${ }^{9}$ Despite the fact of progressive autograft dilation and anticipated need for homograft reinterventions/ operations, long-term data of Ross operation in young adults are still promising. ${ }^{10}$ Further modifications bear the potential to improve long-term aortic root stability and may strengthen the role of the Ross operation as one of the techniques with most consistent and reproducible data. ${ }^{4}$

The quest will continue to find the right technique at the right time in the course of the aortic valve disease for the right patient in the right hands that must consider a combination of several techniques in a well-planned order to ensure the preservation of normal systolic and diastolic ventricular function with the least number of interventions and complications in the longer term. Tissue-engineered heart valves may offer an end to the never-ending open questions by meeting the requirements of the ideal valve substitute. ${ }^{11}$

The courage to decisively apply novel techniques for the surgical treatment of aortic valve disease is of utmost importance. These efforts will add invaluable knowledge toward our ultimate goal of one corrective operation for all types of aortic valve disease in a lifetime for our smallest patients, preferably without a preceding balloon valvuloplasty in the majority. ${ }^{12}$ I congratulate the authors again for their excellent contribution.

\section{References}

1. Harken DE. Heart valves: Ten Commandments and still counting. Ann Thorac Surg. 1989;48:18-9.

2. Nishimura RA, Otto CM, Bonow RO, Carabello BA, Erwin JP, Guyton RA, et al. 2014 AHA/ACC guideline for the management of patients with valvular heart disease: a report of the American College of Cardiology/American Heart Association Task Force on Practice Guidelines. J Am Coll Cardiol. 2014;63:e57-185.

3. Sievers HH, Stierle U, Petersen M, Klotz S, Richardt D, Diwoky M, et al. Valve performance classification in 630 subcoronary Ross patients over 22 years. $J$ Thorac Cardiovasc Surg. 2018;156:79-86.

4. Ungerleider RM, Ootaki Y, Shen I, Welke KF. Modified Ross procedure to prevent autograft dilatation. Ann Thorac Surg. 2010;90:1035-7.

5. Wiggins LM, Mimic B, Issitt R, Ilic S, Bonello B, Marek J, et al. The utility of aortic valve leaflet reconstruction techniques in children and young adults. $J$ Thorac Cardiovasc Surg. 2020;159:2369-78.

6. Ozaki S, Kawase I, Yamashita H, Uchida S, Takatoh M, Kiyohara N. Midterm outcomes after aortic valve neocuspidization with glutaraldehyde-treated autologous pericardium. J Thorac Cardiovasc Surg. 2018;155:2379-87.

7. The Ozaki Procedure with CardioCel patch for children and young adults with aortic valve disease: preliminary experience - a word of caution. World J Pediatr Congenit Heart Surg. 2019;10:724-30.

8. Bell D, Betts K, Justo R, Forde N, Venugopal P, Corno AF, et al. Multicenter experience with 500 CardioCel implants used for the repair of congenital heart defects. Ann Thorac Surg. 2019;108:1883-8.

9. Etnel JR, Elmont LC, Ertekin E, Mokhles MM, Heuvelman HJ, RoosHesselink JW, et al. Outcome after aortic valve replacement in children: a systematic review and meta-analysis. J Thorac Cardiovasc Surg. 2016;151: 143-52.

10. Sharabiani MT, Dorobantu DM, Mahani AS, Turner M, Peter Tometzki AJ, Angelini GD, et al. Aortic valve replacement and the ross operation in children and young adults. J Am Coll Cardiol. 2016;67:2858-70.

11. Rieder E, Seebacher G, Kasimir M, Eichmair E, Winter B, Dekan B, et al. Tissue engineering of heart valves. Circulation. 2005;111:2792-7.

12. Vergnat M, Asfour B, Arenz C, Suchowerskyj P, Bierbach B, Schindler E, et al. Aortic stenosis of the neonate: a single-center experience. $J$ Thorac Cardiovasc Surg. 2019;157:318-26. 